\title{
A Comparative Study of Different Control Methods for Anti-Lock Braking System (ABS)
}

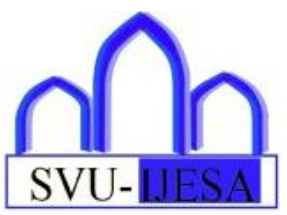

\author{
Shady Ashraf Abd El-Fatah ${ }^{1}$, Abdel-Nasser Sharkawy ${ }^{*}$, Ahmad O. Moaaz ${ }^{2}$, Nouby M. Ghazaly ${ }^{1}$
}

\begin{abstract}
The anti-lock braking system (ABS) can detect the wheels locking and also modulate the brake pressure for preventing the wheel from the locking. The main objective of controlling the ABS is giving the controlled required torque to obtain the optimal wheel slip rate. This slip rate is defined as the function of the linear velocity of automobile as well as the angular wheels' speed.

In this paper, a review of the ABS mechanism and the different applied controllers are presented. The principles, operation, components, advantages, and disadvantages of $\mathrm{ABS}$ are investigated. The controllers applied for ABS are categorized as follows: (ON-OFF) Bang-Bang control, PD controller, PID controller, Fuzzy Logic Controller, and Electronic Braking Force Distribution (EBFD) controller. These controllers are presented using a quarter car model with longitudinal and rotational dynamics. The comparison between these applied controllers is also presented. According to the braking force applied to the braking system, the response is simulated.
\end{abstract}

Received: 6 May 2021 / Accepted: 11 June 2021

*Corresponding Author

Shady Ashraf Abd El-Fatah, sho0o0oksh@gmail.com

Abdel-Nasser Sharkawy, abdelnassersharkawy@eng.svu.edu.eg

Ahmad O. Moaaz, moazz777@eng.bus.edu.eg

Nouby M. Ghazaly, noubyluxor@gmail.com

1 Mechanical Engineering Department, Faculty of Engineering, South Valley University, Qena, 83523, Egypt.

${ }^{2}$ Mechanical Engineering Department, Faculty of Engineering,

Beni-Suef University, Beni Suef, Egypt.
From the comparative study, it is concluded that by controlling the vehicle velocity and the wheel angular speed, the applied Fuzzy Logic controller is better than the PID, PD, and Bang-Bang controllers in reducing the stopping distance and time required for braking. EBFD controller provides the best performance compared with the four previous controllers. Furthermore, the EBFD controller achieves the most stability for a vehicle, particularly, when the vehicle is under adverse road conditions.

KEYWORDS: Anti-Lock Braking System; Different control Techniques; A Comparative Study; Slip Rate; Stopping Distance and Time.

\section{INTRODUCTION}

The first motor-driven vehicle was developed in 1769 and the first accident was occurred in 1770 [1]. Therefore, engineers sought to reduce the driving accidents and to 
improve the vehicles safety. The efficient braking systems design aims to reduce the accidents. The experts in vehicle have developed this field by inventing the first mechanical ABS. This system has been designed and also produced in the aerospace industry in 1930. In 1945, the first ABS set was included on a Boeing B47 for preventing the spinouts and tires from blowing. In the 1950s, ABS was implemented in the airplanes. In the 1960s, high-end automobiles were fitted with the rear only ABS. In 1972, in England, the first application of ABS in cars was implemented [3]. In the 1980s, ABS was widely used and applied. Nowadays, ABS can be existing on most late-model vehicles and even on selected motorcycles [1].

ABS is considered as a crucial contribution for road safety, since it is designed for keeping the vehicle steerable and stable during the heavy moments by preventing the brakes from locking once braking. However, a full auto brake pedal is pushed and therefore skidding does not occur regardless of the road conditions. In the situation of normal braking, the brakes are controlled by the driver. During emergency braking or on the slippery roadways, the ABS controls the wheels. ABS can modulate the brake line pressure independent of the pedal force for bringing the speed of the wheel back to the range of the slip level that is necessary for the optimal performance of braking. ABS does not allow the lock of the full wheel under braking [2].

ABS is a closed circuit; therefore it used the closedloop control system which modulates the brake pressure based on the deceleration of the wheel and angular velocity of the wheel for preventing the controlled wheel from locking [2].

\subsection{THE MAIN CONTRIBUTION}

In this paper, the ABS mechanism is reviewed. Besides, a comparative study is presented to compare quantitively and qualitatively the different applied controllers for ABS. These controllers are (ON-OFF) Bang-Bang control, PD controller, PID controller, Fuzzy Logic Controller, and Electronic Braking Force Distribution (EBFD) controller.

\subsection{THE PAPER OUTLINES}

The rest of this paper is divided into the following sections: section 2 illustrates the simple mechanical brakes. In section 3, the ABS is presented in detail. Section 4 shows the different applied controllers for ABS. Section 4 compares the ABS controllers quantitively and qualitatively. Section 5 summarizes the main important points of this work.

\section{SIMPLE MECHANICAL BRAKES (SMB)}

SMB is the conventional brake system. This system consists of a hydraulic brake circuit. This circuit has the fluid-filled master and the slave cylinders connected by the pipes. When the brake pedal is pushed, it depresses the piston in the master cylinder and therefore the fluid is forced along the pipe. The fluid travels to the slave cylinders on each wheel and fills them, forcing the pistons out for applying the brakes. Around the system, the fluid pressure distributes itself. This system does not need any electronic part [3]. This system is shown in Fig. 1 [4].

The disadvantages of the Simple mechanical brakes are as follows: 1) The stopping distance is long, 2) while emergency braking is performed, the vehicle loses its stability and starts to skid, 3) its effectiveness is low; therefore, the accidents chance is more. Therefore, it was necessary for developing a safety function that automatically works and more efficient. Then there was a need for electronics atomization.

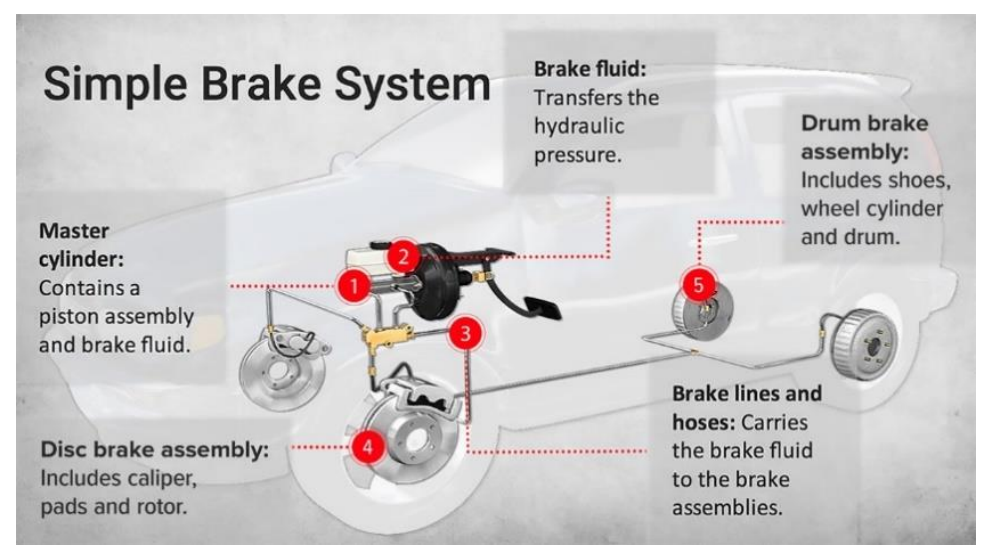

Figure 1. Simple mechanical brakes [4]. 


\section{ANTILOCK BRAKING SYSTEM (ABS)}

ABS is the active safety system in the road vehicles [5]. ABS is considered a crucial factor for keeping a vehicle's steering ability and stability during the maximum braking process by preventing the wheels from locking. In this section, the principles, operations, and components of ABS are discussed.

\subsection{ABS PRINCIPLES}

ABS is the active safety system for vehicles. The ABS is the system which senses when the vehicle's wheels are about to lock during the hard braking, and it releases the brakes. In the case of hard braking, ABS increases the frictional force which happens between the tire and the road regardless of the road conditions. This is achieved by regulating the slip of the wheel around the optimum value.

\subsection{ABS OPERATION}

ABS is composed of: 1) the central electronic control unit (ECU), 2) the four-wheel speed sensors, and 3) at least two hydraulic valves in the brake hydraulics [3]. The ECU monitors constantly the rotational wheel speed. The cars' wheels which are equipped with ABS are impossible to lock even during the panic braking in the extreme conditions. This process is continuously repeated, and it can be detected by the driver via the pulsation of the brake pedal. Some ABSs are able to apply or to release braking pressure 15 times per second. This is the reason that the cars' wheels equipped with ABS are practically impossible to lock even during the panic braking in the extreme conditions.

\subsection{ABS COMPONENTS}

The main components of ABS are presented in Fig. 2. In detail, these components are discussed as follows [3], [4], [6]:

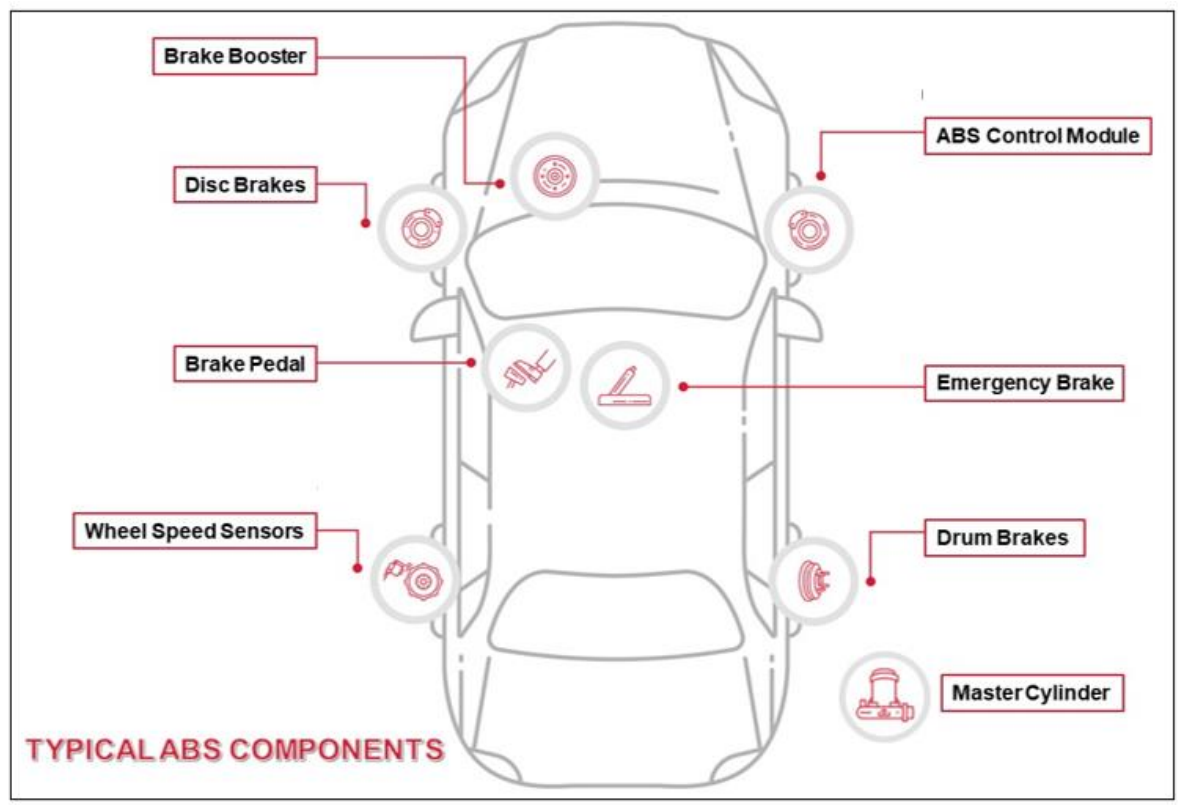

Figure 2. The main ABS components [3], [4], [6]. 


\section{ABS Control Module}

This module is responsible for checking the ABS and also for determining when the required pressure should be sent to each wheel for preventing wheels' locking.

\section{Brake Booster}

This module is responsible for reducing the pressure amount required for braking to give the driver the ability of brakes operating. It uses the vacuum pressure of the engine for increasing the force which the brake pedal puts on the master cylinder.

\section{Disc Brakes}

This module is existing on the front wheels. Disc brakes have brake pads that press against a disc (rotor) when the brake pedal is used for vehicle stopping.

\section{Drum Brakes}

This module is located on the rear of the vehicle. Drum brakes have the wheel cylinders, the brake shoes, and the brake drum. Once the brake pedal is applied, the brake shoes are forced into the brake drum by the wheel cylinders and therefore stopping the vehicle.

\section{Emergency Brake}

This module is known as the parking brake, hand brake, and e-brake. It is used for keeping the vehicle in place when parked.

\section{Master Cylinder}

This module is responsible to convert the non-hydraulic pressure to the hydraulic pressure which the wheel cylinders are used for pressing the brake pads against the rotors to stop the vehicle.

\section{Brake Pedal}

When the driver presses on the brake pedal in order to activate the brakes, the piston found in the master cylinder moves.

\section{Wheel Speed Sensors}

This module is responsible for monitoring the speed of each tire and sending the information to the ABS control module.

\section{DIFFERENT ABS CONTROLLERS AND COMPARISONS}

ABS controlling puts unique challenges to the designer such as [7]: 1) for optimal performance: the controller operates at the unstable equilibrium point, 2) based on the road conditions: the maximum braking torque varies over a wide range, 3) the measurement signal of tire slippage which is important for the performance of the controller is highly noisy and uncertain, 4) on rough roads: the slip ratio of the tire varies rapidly and widely because of the tire bouncing, 5) the coefficient of friction of the brake pad is changing, and finally 6) the braking system includes the transportation delays which limit the bandwidth of the control system [8].

In this section, the different control methods such as Bang-Bang, PD, PID, Fuzzy Logic, and EBFD are compared for ABS using the quarter vehicle model (see Fig. 3).

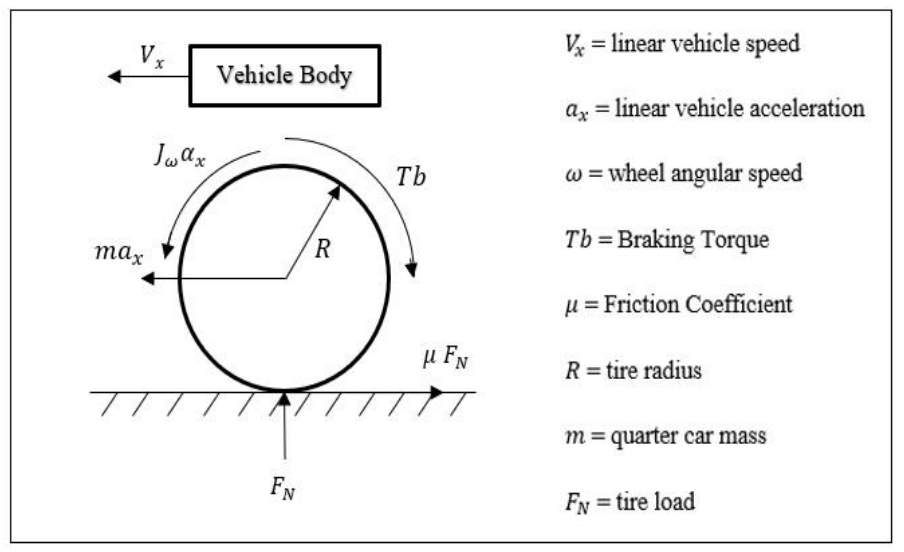

Figure 3. Quarter car braking model [9]-[11].

The vehicle linear speed and the wheel rotational speed constitute the degrees of freedom for this model. The equations governing the vehicle movements are presented as follows [12]:

$m a_{x}=-\mu F_{N} \rightarrow m \frac{d v_{x}}{d x}=-\mu F_{N}$

The torque at the wheel center:

$J_{\omega} \alpha_{\omega}=\mu R F_{N}-T_{b} \rightarrow J_{\omega} \dot{\omega}=\mu R F_{N}-T_{b}$

The slip ratio is presented as:

$S=\frac{v_{x}-\omega \mathbf{R}}{v_{x}}$

By differentiating equation (3) with respect to time, then we get

$S=\frac{\dot{v}_{x}(\mathbf{1}-\mathbf{S})-\dot{\boldsymbol{\omega}} \mathbf{R}}{v_{x}}$ 
The relationship between the friction coefficient and the wheel slip ratio presents the ability of the ABS for maintaining the steering and the vehicle stability while reducing the stopping distances. The friction coefficient is a function of the automotive speed and the tire slip rate [13]. The factors as the road conditions, the slip angle, the tire type, the vehicle speed, and the wheel slip ratio are responsible for changing the friction coefficient more.

$\left.\mu\left(S, v_{x}\right)=\left[c_{1}\left(1-e-c_{2} S\right)-c_{3} S\right)\right] e-c_{4} v_{x}$

where, $c_{1}$ is the friction curve the maximum value, $c_{2}$ is the friction curve shapes, $c_{3}$ is the difference between the maximum value and the value at $S=1$ in friction curve, and $c_{4}$ is the road wetness characteristic value.

\subsection{A SURVEY TO BANG-BANG, PD, AND PID CONTROL}

\subsubsection{BANG-BANG CONTROL}

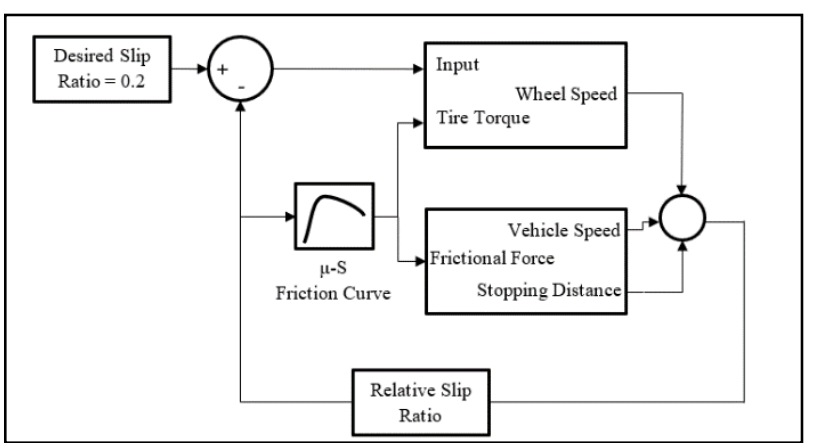

Figure 4. Bang-Bang Control system for ABS [9], [14].

The ABS braking system that employs the BangBang control is based on the error between the actual slip ratio and the desired one, as shown in Fig. 4. The desired value of the slip ratio is the value at which $\mu$-S (friction coefficient with respect to slip ratio) gives the maximum value which is the value that reaches the minimum braking distance [9].

The advantage of using Bang-Bang control system is that it is simple system with the limited inputs. The disadvantages of the Bang-Bang control system are that this controller is poor and its limited range between on and off. In addition, it is not sensitive.

\subsubsection{PROPORTIONAL DERIVATIVE FEEDBACK CONTROL (PD CONTROL)}

This controller uses the error gain $\left(K_{p}\right)$ and the error differentiation gain $\left(K_{d}\right)$ for maintaining the output at the desired point as presented in Fig. 5 and the following equation [9], [15]:

$$
u=K_{p} \mathrm{e}+K_{d}(d e / d t)
$$

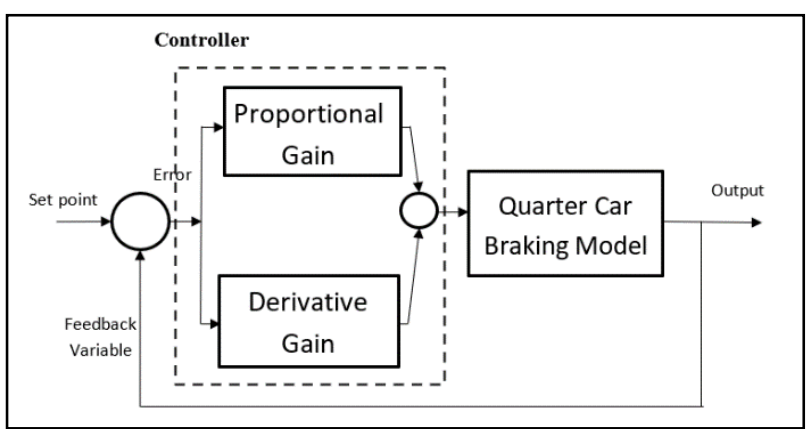

Figure 5. PD controller for quarter car braking model.

Using PD Control has a lot of advantages such as: the maximum overshoot is decreasing, the rise time and the settling time are reducing, and the bandwidth is increasing. However, it has some disadvantages such as the offset and the steady-state error [16]. Therefore, there is a need to develop the PID controller to overcome the disadvantages of the PD control.

\subsubsection{PROPORTIONAL INTEGRAL DERIVATIVE FEEDBACK CONTROL (PID CONTROL)}

The equation of PID control is presented in the following equation [9], [17]:

$u=K_{p} \mathrm{e}+K_{d}(d e / d t)+K_{i} \int e d t$

where, $K_{p}, K_{i}$ and $K_{d}$ are the gains of proportional, integral and the derivative controllers respectively [18]. PID control for the quarter car braking model is presented in Fig. 6. The main advantages of PID are decreasing the rise time, the overshoot, and the settling time. In addition, it eliminates the steady-state error [16].

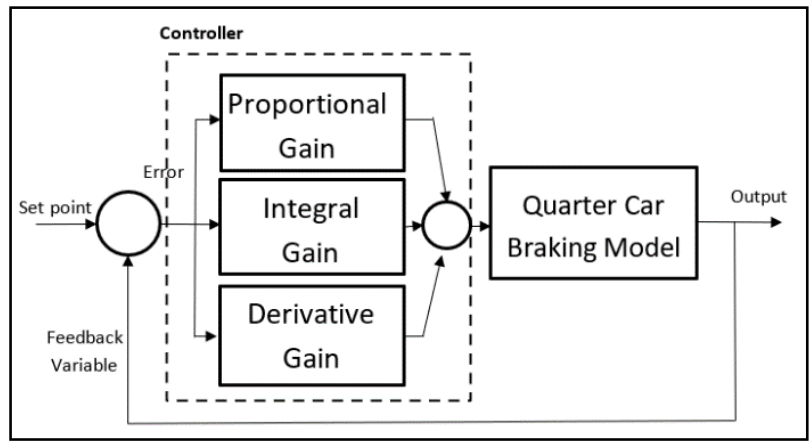

Figure 6. PID controller for quarter car braking model. 
4.2. COMPARISON BETWEEN BANG-BANG, PD, AND PID CONTROL

The results of applying the Bang-Bang, PD, PID control methods for ABS in terms of the stopping time and distance are presented in Table 1 [9], [14].

†Table 1: Comparison between Bang-Bang, PD and PID Control system for ABS [9], [14].

\begin{tabular}{|c|c|c|}
\hline ABS Controller & $\begin{array}{c}\text { Stopping } \\
\text { Time (s) }\end{array}$ & $\begin{array}{c}\text { Stopping } \\
\text { Distance (m) }\end{array}$ \\
\hline $\begin{array}{c}\text { Without control } \\
\text { systems }\end{array}$ & 4.5 & 50 \\
\hline Bang-Bang Control & 2.668 & 31.21 \\
\hline PD control Type & 2.4 & 24 \\
\hline PID control type & 2.319 & 23.61 \\
\hline PID control type & 4.5 & 50 \\
\hline
\end{tabular}

As presented in Table 1, the PID control achieves the best performance compared with the Bang-Bang and the PD controls. With applying PID control, the time and the distance required for stopping the vehicle are the lowest.

\subsection{FUZZY LOGIC CONTROL FOR ABS}

Because of PID controller is a linear controller, but the relationship between tire and road is highly nonlinear, therefore PID is not effective when the slip ratio values are large [11]. In addition, there is a clear limitation of its performance and it does not possess the enough robustness for the practical implementation [1].

For maintaining a constant predefined slip ratio and adapting to the road conditions, the Fuzzy Logic control system is designed which is able to change the desired slip ratio value with the changes in the conditions of the road. The fuzzy logic control system for the quarter car braking model is presented in Fig. 7.

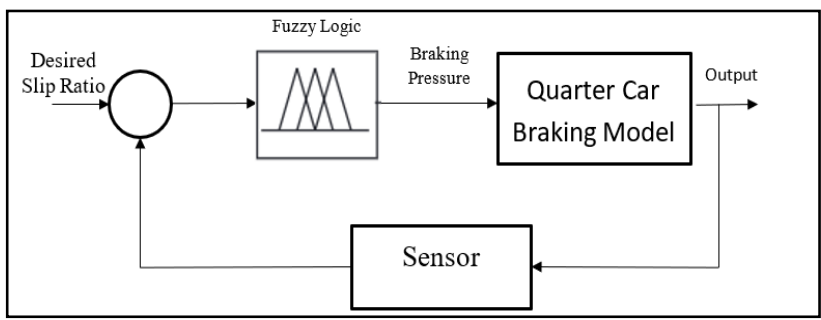

Figure 7. Fuzzy controller for quarter car braking model

\footnotetext{
[14].

$\dagger$ The values presented in Table 1 are obtained from references [9],
}

The results of applying the PID and the Fuzzy Logic controls for ABS in terms of the stopping time and distance are presented in Table 2 [1], [7], [19].

*Table 2. Comparison between PID and Fuzzy Logic Control system for ABS [1], [7], [19].

\begin{tabular}{|c|c|c|c|}
\hline $\begin{array}{c}\text { ABS } \\
\text { Controller }\end{array}$ & $\begin{array}{c}\text { Stopping } \\
\text { Time (s) }\end{array}$ & $\begin{array}{c}\text { Overshoot } \\
\text { \% }\end{array}$ & $\begin{array}{c}\text { Stopping } \\
\text { Distance } \\
\text { (m) }\end{array}$ \\
\hline PID control & 128 & 11 & 568 \\
\hline $\begin{array}{c}\text { Fuzzy } \\
\text { Logic } \\
\text { control }\end{array}$ & 56 & 0 & 524 \\
\hline
\end{tabular}

From the results presented in Table 2, the fuzzy logic controller is better than the PID controller. The stopping time and distance and the overshoot are the lowest in the case of using the fuzzy logic controller.

\subsection{ELECTRONIC BRAKEFORCE DISTRIBUTION (EBFD)}

The electronic brake force distribution (EBFD) system is the automobile brake technology which varies automatically the amount of applied force to each of the brakes of the vehicle, based on the road conditions, the speed, and the loading.

EBFD is similar in many ways to ABS. Both systems are installed together as presented in Fig. 8. ABS can prevent the wheels from locking by sensing the wheel lockage threat and then releasing and applying the brakes in the rapid succession. The main difference between EBFD and ABS is that EBFD changes the amount of the brake-force which is applied to any given wheel based on the wheel locking likelihood. The added benefit of being able to redistribute the brake-force makes EBFD the particularly useful extension of standard ABS setups [3].

The main comparison between the ABS with EBFD and the ABS without EBFD is presented in Fig. 9. and in Table 3 .
$\$$ The values presented in Table 2 are obtained from references [1], [7], [19]. 


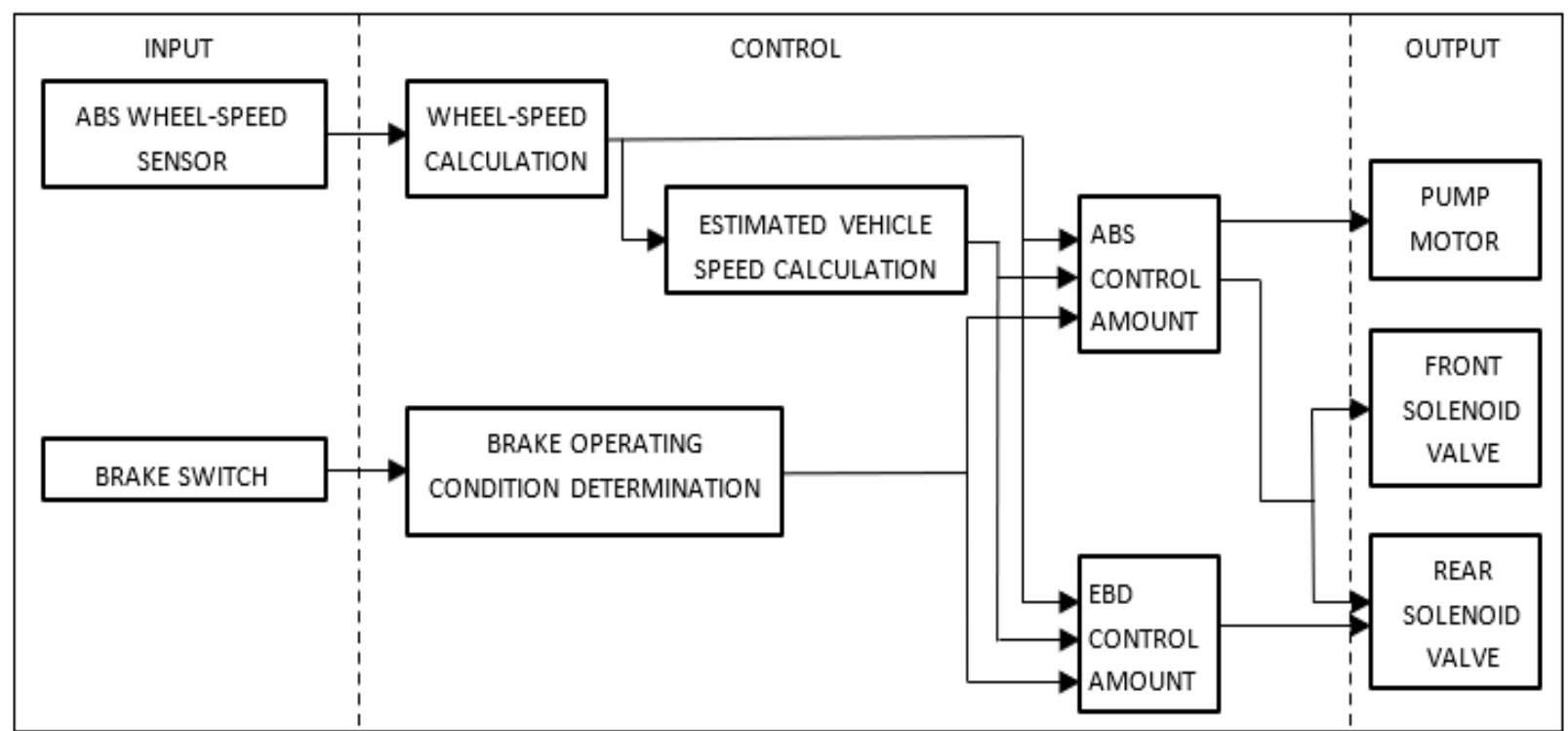

Figure 8. Block diagram of EBFD operation [3].

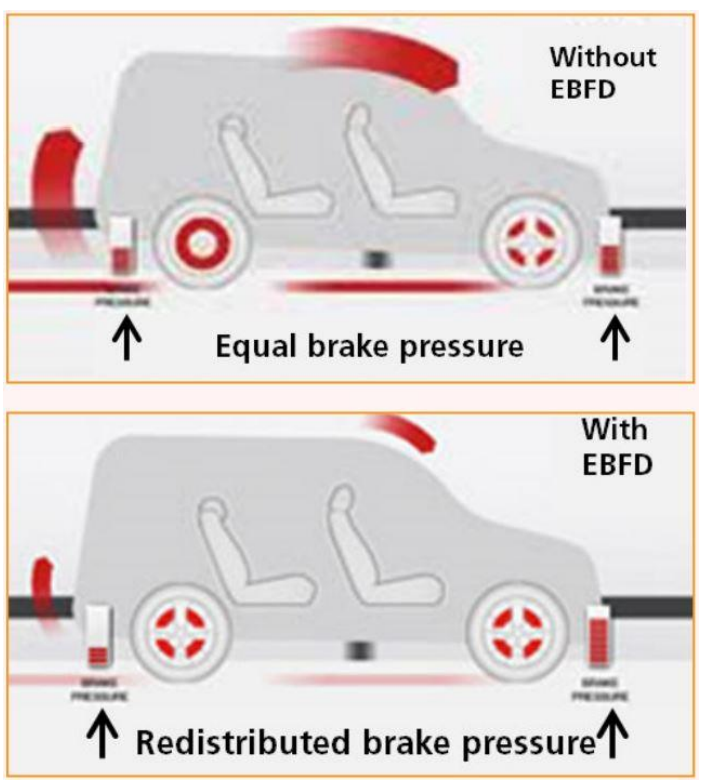

Figure 9. Difference between ABS system with EBFD and ABS system without EBFD [20].
Table 3: Comparison between ABS with EBD and Without [3].

\begin{tabular}{|c|c|}
\hline ABS with EBFD & ABS without EBFD \\
\hline $\begin{array}{c}\text { It simultaneously } \\
\text { controls the individual } \\
\text { wheel. }\end{array}$ & $\begin{array}{c}\text { It controls cross the } \\
\text { wheels }\end{array}$ \\
\hline $\begin{array}{c}\text { Vehicle will stop } \\
\text { immediately even if it is } \\
\text { loaded. }\end{array}$ & $\begin{array}{c}\text { Stopping distance of } \\
\text { vehicle is more when it is } \\
\text { loaded. }\end{array}$ \\
\hline $\begin{array}{c}\text { This braking system is } \\
\text { effective in adverse road } \\
\text { conditions like snow. }\end{array}$ & $\begin{array}{c}\text { ABS is not effectively } \\
\text { work under adverse road } \\
\text { conditions. }\end{array}$ \\
\hline The cost is less & $\begin{array}{c}\text { Manufacturing cost is } \\
\text { more }\end{array}$ \\
\hline
\end{tabular}

EBFD is useful at speeds under a certain threshold. The faster you drive, the longer it will take to stop safely. Beyond a certain speed, you cannot combine EBFD braking power with safe steering input. Excessive speed can seriously limit the benefit of EBFD and, in worsecase scenarios, make it impossible for your vehicle to be stabilized in an emergency. The EBFD effectiveness is dependent to a large extent on the decisions the driver makes in the moments right before, during, and right after a period of heavy braking [20]. 


\section{CONCLUSIONS}

In this paper, the ABS mechanism is presented in detail. $\mathrm{ABS}$ is one of the most important safety features provided by the automobile industry by the use of the electronics engines. ABS system can reduce the vehicle braking distance, increases the efficiency of the tire, and maintains the stability of the vehicle.

The second part of this paper studies the different applied controllers for ABS. A comparison between these controllers is presented in terms of the stopping time and the stopping distance as well. The study shows that the fuzzy logic control presents the best performance compared with the Bang-Bang, PD, and PID control in reducing the overshoot, the stopping time, and stopping distance.

However, some disadvantages are found such as its performance get down in the adverse road conditions. For overcoming this disadvantage, the automobile industry has made a new advancement in the ABS which is known as EBFD. EBFD provides more stability to the vehicle under adverse road conditions as well as the braking distance of the vehicle gets reduced.

\section{REFERENCES}

[1] A. A. Aly, E. Zeidan, A. Hamed, and F. Salem, "An Antilock-Braking Systems ( ABS ) Control : A Technical Review," Intell. Control Autom., no. 2, pp. 186-195, 2011.

[2] S. Jitesh, "ANTILOCK BRAKING SYSTEM ( ABS )," Int. J. Mech. Eng. Rob. Res. 2014 Res., vol. 3, no. 4, pp. 253-259, 2016.

[3] D. Khachane and P. A. Shrivastav, "Antilock Braking System and Its Advancement," Int. Res. J. Eng. Technol., vol. 3, no. 5, pp. 2221-2225, 2016.

[4] "Complete Guide to Disc Brakes and Drum Brakes", https://www.lesschwab.com/article/complete-guide-todisc-brakes-and-drum-brakes.html.

[5] S. John and J. O. Pedro, "Hybrid Feedback Linearization Slip Control for Anti-lock Braking System," Acta Polytech. Hungarica, vol. 10, no. 1, pp. 81-99, 2013.

[6] "ABS Components", https://www.ingenieriaymecanicaautomotriz.com/antilock-braking-system-abs-components-types-andworking-principle/.

[7] Y. Yazicioglu and Y. Samim Unlusoy, “A fuzzy logic controlled Anti-lock Braking System (ABS) for improved braking performance and directional stability," Int. J. Veh. Des., vol. 48, no. 3-4, pp. 299-315, 2008.

[8] G. F. Mauer, "A Fuzzy Logic Controller for an ABS Braking System,” IEEE Trans. Fuzzy Syst., vol. 3, no. 4, pp. 381-388, 1995.
[9] A. O. Moaaz, A. S. Ali, and N. M. Ghazaly, "Investigation of Anti-Lock Braking System Performance Using Different Control Systems," Int. J. Control Autom., vol. 13, no. 1 , pp. 137-153, 2020 .

[10] J. Pedro, O. Dahunsi, and O. T. Nyandoro, "Direct adaptive neural control of antilock braking systems incorporated with passive suspension dynamics Direct adaptive neural control of antilock braking systems incorporated with passive suspension dynamics," J. Mech. Sci. Technol., vol. 26, no. 12, pp. 4115-4130, 2012.

[11] I. Hussain, K. Kazi, and A.A. Patoli, "Fuzzy Logic Based Effective Anti-Lock Braking System Adaptive to Road Conditions Fuzzy Logic Based Effective Anti-Lock Braking System Adaptive to Road Conditions," in First International Conference on Modern Communication \& Computing Technologies (MCCT'14)At: Nawabshah Pakistan, 2014.

[12] Y. He, C. Lu, J. Shen, and C. Yuan, "Design and analysis of output feedback constraint control for antilock braking system based on Burckhardt's model," Assem. Autom., vol. 39, no. 4, pp. 497-513, 2019.

[13] P. E. Wellstead, "Analysis and Redesign of an Antilock Brake System Controller," IEEE Proc. Control Theory Appl., vol. 144, no. 5, pp. 413-426.

[14] D. G. V and A. C. Ramachandra, "Slip Ratio Control of Anti-Lock Braking System with Bang-Bang Controller Abstract :," Int. J. Comput. Tech., vol. 4, no. 1, pp. 97-104, 2017.

[15] A. N. Sharkawy and P. N. Koustoumpardis, "Dynamics and computed-torque control of a 2-DOF manipulator: Mathematical analysis," Int. J. Adv. Sci. Technol., vol. 28, no. 12, pp. 201-212, 2019.

[16] "Comparison between P, PI, PD and PID controllers", https://forumautomation.com/t/comparison-between-ppi-pd-and-pid-controllers/4922.

[17] A. E.-N. S. Ahmed, A. S. Ali, N. M. Ghazaly, and G. T. Abd el-Jaber, "PID controller of active suspension system for a quarter car model," Int. J. Adv. Eng. Technol., vol. 8, no. 6, pp. 899-909, 2015.

[18] M. M. Ali, A. R. Youssef, A. S. Ali, and G. T. Abdel-Jaber, "Comparative study of different pitch angle control strategies for DFIG based on wind energy conversion system," Int. J. Renew. Energy Res., vol. 9, no. 1, pp. 157163, 2019.

[19] M. Singh, A. Rani, and V. Singh, "Wheel Slip-Based Intelligent Controller Design for Anti-Lock Braking System," Adv. Res. Electr. Electron. Eng. Print, vol. 1, no. 3, pp. 82-88, 2014.

[20] BrainonBoard.ca, "Electronic Brake-Force Distribution (EBFD)," Brain on Board. 